\title{
Patterns and Biases of Climate Change Threats in the IUCN Red List
}

Short title: IUCN and Climate Change Threat

\author{
Nicholas Trull ${ }^{*}$, Monika Böhm² and Jamie Carr ${ }^{3}$ \\ * Corresponding author: trullnicholas@yahoo.co.uk
}

\section{Affiliations:}

1 - Independent researcher, Cambridge, United Kingdom. Email: trullnicholas@ yahoo.co.uk

2 - Institute of Zoology, Zoological Society of London, Regent's Park, London NW1 4RY, United Kingdom. Email: monika.bohm@ioz.ac.uk

3 - Global Species Programme, International Union for Conservation of Nature, Cambridge, United Kingdom. Email: jamie.carr@iucn.org

Keywords: Red List, Climate Change, Amphibians, Birds, Habitat, Vulnerability, Traits

Word count (Abstract to last word in Literature Cited): 6,715

\section{Acknowledgements}

MB receives generous support from The Rufford Foundation and the ZSL Mission Opportunities Fund. 


\section{Patterns and Biases of Climate Change Threats in the IUCN Red List}

\section{Abstract}

The IUCN Red List of Threatened Species assesses species' extinction risk to catalyse conservation action. Assessments rely on published data and expert inputs; it has been suggested that biases can be introduced where underlying definitions and concepts are ambiguous. Consideration of climate change threat is no exception to this, and recently climate change-specific assessments using numerous different approaches have been developed (see Foden and Young 2016 for background and a review). We explored global Red List assessments for amphibians and birds to examine whether species with/without an acknowledged climate change threat display patterns in terms of (a) the habitat types they occupy, and (b) additional non-climatic threats they face. We compared these Red List data to a published dataset of biological and ecological traits believed to infer high vulnerability to climate change, and asked whether (a) distributions of climate change-threatened species on the Red List concur with those of climate change-vulnerable species identified using this trait-based approach, and (b) species possessing these traits are more likely to have climate change threat listed on the Red List. We found that a number of habitats (e.g. grassland, shrubland) and threats (e.g. invasive and problematic species) were associated with an increased likelihood of having climate change as a listed threat. Geographical patterns of climate change-threatened amphibian and bird species on the Red List are incongruent with those of global species richness and with patterns identified using trait-based approaches. Certain traits are linked to an increase or decrease in the likelihood of a species being climate change-threatened. Broad temperature tolerance consistently related to an increased likelihood of climate change threat, indicating the presence of starkly counterintuitive relationships between IUCN assessments. We examine these findings and make 
recommendations to improve the robustness of species assessments of the vulnerability or extinction risk associated with climate change.

\section{Introduction}

The IUCN Red List of Threatened Species (hereafter 'IUCN Red List') is regarded as the most comprehensive index of global species extinction risks. It provides assessments of the status and trends of species to catalyse conservation action. Assessments of species rely on published data and expert input on factors relating to each species' extinction risk (e.g. distribution, population status, ecology, threats). Given the role of expert inputs, it has been suggested that bias is introduced into assessments where underlying definitions and concepts are ambiguous (Hayward et al. 2015); however, most assessments are facilitated in working groups where best available data are used to estimate quantitative extinction risk thresholds, thus minimising bias through unstructured expert opinion (Collen et al. 2016).

Assessment of predominant threat processes affecting species is likely to be more complicated, due to a lack of direct evidence on the interactions between different threats (Brook et al. 2008). Specifically, it has been suggested that the IUCN Red List protocol does not adequately reflect the risk posed to species by slow-acting threats such as climate change (Thomas et al. 2004; Keith et al. 2014). Although it has been shown that IUCN Red List Criteria effectively account for climate change in threatened species (Akçakaya et al. 2014; Pearson et al. 2014), climate change is stated as the sole threat for $939(1.18 \%)$ of the total 79,837 assessed species, and 6.3\% of amphibians and 10.2\% of birds (IUCN 2016b), despite being an emerging threat to a large number of species (Foden et al. 2013). Most often, climate change threat on the IUCN Red List occurs in combination with other threats. Overall, the IUCN Red List identifies climate change as a threat for 2,560 (11\%) of the 
23,250 species listed as threatened (categories of Vulnerable, Endangered or Critically Endangered; (IUCN 2016b)). Compared to Thomas et al.'s (2004) earlier estimates of 18$35 \%$ of species 'committed to extinction' by 2050 , the IUCN Red List apparently understates climate change as a threat to species.

This may be because IUCN Red List assessments generally focus on assessing extinction risk over relatively short time-scales (three generations or 10 years, whichever is longer (IUCN Standards and Petitions Subcommittee 2016)). Climate change impacts can develop over long time scales, and can be hard to differentiate from natural phenomena (Akçakaya et al. 2006). Furthermore, there remains significant uncertainty around the mechanisms by which climate change will affect species, particularly when considering changes to interspecific interactions (Bellard et al. 2012). Resultantly, other threats may be easier observed and quantified, and thus understood and recorded, resulting in underestimations of the importance of climate change on the IUCN Red List (Hof et al. 2011).

Although IUCN encourages the consideration of climate change impacts, they simultaneously acknowledge the difficulties of doing so (IUCN Standards and Petitions Subcommittee 2016). Consequently, assessors may use a process of judgement or anticipation when recording a species' climate change-related threat, and it is likely that some biases or inconsistencies will be introduced at this stage; for example, assessors may be more inclined to recognise or acknowledge the threat of climate change to species occurring in particular habitats or geographic areas, or for species with certain biological or life-history traits.

To complement existing processes of estimating extinction risk, climate change-specific assessments have been developed using a number of different approaches, ranging from mechanistic models to trait-based assessments (Pacifici et al. 2015). Trait-based climate change vulnerability assessments (CCVA) have been advocated by the IUCN (Foden et al. 
2013; Carr et al. 2014), and use species-specific trait data to infer high or low vulnerability to climate change. Traits used in these analyses generally pertain to climate change sensitivity and low adaptability of species, and are coupled with measures of climate change exposure (Foden et al. 2013).

Extensive datasets are available containing climate change-relevant trait data of species, from which to assess whether certain species and their traits are more likely to be associated with climate change threat on the IUCN Red List. Here, we focus on traits and factors related to CCVA of species (Foden et al. 2013) to evaluate whether any of these traits and factors coincide with the reporting of climate change as a threat on the IUCN Red List. Specifically, we hypothesize that a) geographical distributions of climate change threat on the IUCN Red List concur with climate change vulnerability from CCVAs; b) species in climate changeaffected habitats (e.g. dry/arid habitats or freshwaters) are more likely to be associated with climate change threat on the Red List; c) the presence of other threats makes a climate change threatened listing more likely; and d) species with CCVA traits indicating vulnerability of a species are more likely to have climate change listed as a threat on the IUCN Red List. In conducting these analyses, we acknowledge that both of the underlying datasets are likely approximations of the truth, and that it remains unclear which one (if either) is the more correct presentation of climate change threat. Nevertheless, we believe that by identifying areas of (dis)agreement between the two datasets, we can indicate areas of greater certainty in terms of climate change threat assessment, as well as areas where further research is recommended.

\section{Methods}

\section{Data sources}


We used two datasets for our analysis: 1) IUCN Red List data and associated species distribution polygons (representing each species' estimated global range) for 6,375 amphibians and 10,280 birds (www.iucnredlist.org; exported January 2015), including all taxonomic, geographic, habitat and threat information; 2) a CCVA dataset of species traits of the world's birds and amphibians, collated by Foden et al. (2013) for 6,204 amphibians and 9,856 bird species (see Supporting Information). Using this CCVA data, we focused on traits pertaining to sensitivity (six variables for amphibians; eight for birds) and adaptability (three variables for amphibians; five for birds) to climate change (see Supporting Information). These traits are used to classify a species as having high sensitivity or low adaptability to climate change, respectively (see Foden et al. 2013).

\section{Data processing}

IUCN Red List assessments use a threat classification scheme of 99 threat types under 12 broad classifications (referred to as Level 1 threat classifications hereafter) and a number of finer-scale sub-categories (Level 2 and Level 3 threat classifications), based on Salafsky et al. (2008) (see Supporting Information). Based on this, we assigned each species to one of two categories: (i) those with climate change as a recorded threat on the IUCN Red List (hereafter 'climate change-threatened species', irrespective of the species' Red List category; 395 amphibians and 1,038 birds) and (ii) those without a climate change threat listed $(5,979$ amphibians and 9,242 birds). Additionally, we used Level 1 and 2 threat classifications to assess associations of climate change-threatened species with other threat types on the IUCN Red List.

Similarly, we derived habitat associations based on the IUCN Red List habitat classification scheme, comprising 103 habitat types under 18 broad classifications (Level 1 habitat 
classifications) and again a number of finer-scale sub-categories (Level 2 and Level 3 habitat classifications; (IUCN 2016a); see Supporting Information). We analysed Level 1 and Level 2 habitat classifications separately, to assess broad-scale (Level 1) habitat associations of climate change-threatened species followed by more in-depth analyses of specific (Level 2) habitat types.

\section{Species richness maps}

In ArcGIS 10.2 (ESRI 2011), we produced global species richness maps for all bird and amphibian species on the IUCN Red List, and additional maps showing climate changethreatened species only. For each, we overlaid a 10 arc-minute hexagonal grid with global coverage onto the stacked species' distribution polygons obtained from the IUCN Red List and calculated the number of species per grid cell using the IUCN Species Mapping Tool for ArcGIS (http://www.iucnredlist.org/technical-documents/red-list-

training/iucnspatialresources). We also calculated and mapped the proportion (of the total present) of species classified as climate change-threatened per grid cell.

\section{Statistical analyses}

We removed Data Deficient species and species in extinct categories from all analyses. We tested associations of climate change-threatened species with habitat type and threats using binomial logistic regression (LR) analyses. Climate change-threatened status of a species was the binary response variable $(1$ or $0=$ climate change threat recorded or not recorded, respectively). Habitat type and threat type were the predictor variables (themselves binomial, e.g. $1 / 0=$ present/not present in forest habitat, and so on), though in separate analyses. To avoid small sample sizes for threats and habitat types affecting our analyses, we excluded predictor variables which contributed less than $1 \%$ of the total number of species in the dataset. Following analysis of Level 1 habitat and threat classifications, analyses using Level 
2 habitat and threat classifications as predictor variables were limited to those for which the corresponding Level 1 predictor variables were significant $(\mathrm{p}<0.05)$.

All LR analyses used a log-log link function to account for unequal response variable group sizes due to fewer species with a reported climate change threat than without. Subsequent to collinearity checks, a stepwise reduction method was used to produce minimum adequate models (MAMs). Following the approach by Burnham and Anderson (2002), we used a delta-AIC less than two to account for uncertainty in model selection. We calculated odds ratios for all analyses as a measure of association between predictor variables and species' climate change-threatened statuses.

To analyse whether species with CCVA traits used to infer climate change vulnerability are already associated with the IUCN Red List threat of climate change, we first matched the taxonomy of the two datasets to produce matching species lists. The removal of species not present in both datasets resulted in a final dataset of 4,429 amphibian and 9,129 bird species, both with available IUCN Red List and CCVA trait data.

Separation of climate change-threatened/unthreatened species resulted in lists of 332 and 934 affected, and 4,097 and 8,195 unaffected, birds and amphibians, respectively. We conducted stepwise binomial logistic regressions using the binary response variable of climate changethreatened species status with CCVA traits as the predictor variables (mixture of continuous and categorical variables, see Supporting Information for full details). To account for complete separation in our bird data, we conducted a Firth's bias reduced logistic regression using the 'logistf' package (Heinze et al. 2013). We constructed MAMs for both taxonomic groups, and calculated odds ratios for all significant variables to measure the strength of the association of climate change-threatened status with CCVA traits. We then repeated our analysis on subsets representing the most speciose taxa in both the amphibian and the bird 
data [amphibians: order Anura $(\mathrm{N}=3,887)$, family Hylidae $(\mathrm{N}=643)$; birds: order Passeriformes $(\mathrm{N}=5,725)$ and family Tyrannidae $(\mathrm{N}=407)]$ to assess the influence of the most speciose groups on our overall results.

Lastly, we constructed full MAMs of climate change-threatened status of species, using all significant explanatory variables (combining habitat, threats and CCVA traits) from the previous models as explanatory variables for birds and amphibians using a stepwise reduction method. All statistical analyses were carried out in R version 3.2.0 (R Core Team 2015).

\section{Results}

\section{Richness of climate change-threatened species}

Amphibian richness is greatest in the Amazon region, and to a lesser degree in the African (e.g. Cameroon and Gabon) and Southeast Asian tropics (e.g. Thailand, Malaysia and Indonesia) (Fig. 1A). Distribution of climate change-vulnerable amphibians roughly corresponds to overall species richness, though total numbers are much smaller (Fig. 1B). Overall richness and proportions of climate change-threatened amphibians did not follow the same distribution; instead high richness of climate change-threatened amphibians was found in eastern China and Korea (Fig. 1C), with high proportions of climate change-threatened amphibians extending from China and Korea northward into Russian Siberia (Fig. 1E). Areas containing high proportions of climate change-threatened amphibians were typically low in overall richness and arid in nature, and include regions of the Sahel and Sahara Deserts in Africa, the Gobi Desert in China, and the Taklamakan Desert in China and Turkmenistan.

Bird species richness was highest in the Amazon region, and across much of sub-Saharan Africa and parts of Southeast Asia (Fig. 2A). Richness of climate change vulnerable birds reflected overall bird species richness within the Amazon region, but not elsewhere (Fig. 2B). 
Richness of climate change-threatened birds was highest in areas of south-eastern Australia and the southern tip of South Africa, and generally low in tropical Africa and Southeast Asia (Fig. 2C). Alaska, Canada, northern Scandinavia and Russia also contained relatively high numbers of climate change-threatened bird species. Proportions of climate change-threatened birds increased towards polar regions (Fig. 2E).

\section{Habitat associations of climate change-threatened species}

\section{Amphibians}

Using Level 1 habitat classifications, occurrence in grassland and shrubland was significantly associated with climate change-threat (Table 1). Using Level 2 habitat classifications, significant associations of subtropical and tropical grasslands and dry shrublands with climate change-threatened amphibians persisted. However, amphibians associated with seasonally wet or flooded lowland grasslands or moist shrublands in tropical or subtropical regions were significantly less likely to be climate change-threatened.

Amphibians associated with artificial terrestrial habitats (e.g. heavily degraded former forest in tropical or subtropical regions) or savanna habitats (e.g. moist savanna) were significantly less likely to be climate change-threatened. Amphibians associated with arable land were significantly more likely to be climate change-threatened.

The same Level 1 habitat associations held true for Anurans, while for Hylidae, there were no significant habitat associations recorded (Table S7).

\section{Birds}

Species associated with the broad-scale habitats of grassland, marine intertidal or marine neritic were significantly more likely to be climate change-threatened (Table 1). No finerscale associations were significant predictors of climate change-threatened birds. 
Species associated with artificial terrestrial, forest or savanna habitats were significantly less likely to be climate change-threatened. Within these broad-scale habitat categories, species associated with: arable land; heavily degraded former forest in tropical and subtropical regions; dry, moist lowland, moist montane or swamp forests of the tropics or subtropics; or dry savanna were significantly less likely to be climate change-threatened.

Level 1 habitat associations were different when only considering the largest bird order, the Passeriformes: of the marine habitats, only marine intertidal remained significant. In addition to artificial-terrestrial, forest and savanna habitats which reflected the patterns seen across all birds, shrubland habitats were associated with a likelihood of being associated with climate change threat, while wetlands and deserts were not associated with climate change threat on the IUCN Red List (Table S8). For Tyrannidae, there were no significant habitat associations with climate change threat.

\section{Threat associations of climate change-threatened species}

\section{Amphibians}

Species were significantly more likely to be climate change-threatened if they were also reported to be affected by the Level 1 threats of: human intrusions and disturbance; invasive and other problematic species; natural system modifications; or pollution (Table 2). The same Level 1 threat associations were found in both the Anuran and Hylidae datasets, with the exception of human intrusion and disturbance, which was no longer significant (Table S7). Using Level 2 threat classifications, species were significantly more likely to be climate change-threatened if they were affected by recreational activities; non-native invasive species; fire and fire suppression; or agricultural and forestry effluents.

\section{Birds}


Species were significantly more likely to be climate change-threatened if they were also reported to be affected by the Level 1 threats of agriculture and aquaculture; human intrusions and disturbance; invasive and other problematic species or natural system modifications (Table 2). Within these broad-scale, Level 1 threat categories, species were significantly more likely to be climate change-threatened if they were reportedly affected by the Level 2 threats of annual and perennial non-timber crops; recreational activities; work and other non-specified activities causing disturbance; non-native invasive species; problematic native species; or fire and fire suppression.

Among Passeriformes, agriculture/aquaculture, invasive or other problematic species and natural systems modifications retained their significant associations with climate change threat, while also including positive interactions with biological resource use in the MAM (Table S8). For Tyrannidae, only residential and commercial development was significantly associated with a likelihood of climate change threat on the IUCN Red List.

\section{Vulnerability traits as predictors of climate change threat on the IUCN Red List}

\section{Amphibians}

Amphibians were significantly more likely to be listed as climate change-threatened on the IUCN Red List if they had a broad temperature tolerance or a narrow precipitation tolerance, were recorded as being susceptible to Chytrid fungus, or had extrinsic barriers to dispersal (e.g. mountain tops, ocean etc.) (Table 3). Conversely, species were significantly less likely to be listed as climate change-threatened if they were dependent on a specific microhabitat, while non-microhabitat-dependent species were more likely to be listed as climate changethreatened. The same traits remained the most significant factors in the Anuran dataset; however, for Hylidae, only temperature tolerance remained significant, with a broad 
temperature tolerance being associated with listing as climate change-threatened on the IUCN Red List.

\section{Birds}

Species with broad temperature tolerances, narrow precipitation tolerances, small population sizes, extrinsic barriers to dispersal, low genetic diversity, and slow turnover of generations were significantly more likely to be climate change-threatened (Table 3). Conversely, species with a low reproductive capacity or microhabitat-dependencies (on bamboo and rocky outcrops) were significantly less likely to be climate change-threatened.

\section{Full model results}

\section{Amphibians}

Combining all significant factors from previous models, occurrence in grassland remained as the only significant habitat factor associated with a likelihood of being climate changethreatened (Table 4). All threat factors from the previous analysis were retained in the full model, each being associated with a climate change-threatened status. Of the CCVA traits, all were retained except habitat specialism, which was no longer statistically significant. Again, microhabitat-dependence and a wide precipitation tolerance were associated with an absence of climate change threat.

\section{Birds}

Of all the previously significant habitats, only marine neritic was retained in the full model as significantly associated with climate change threat (Table 4). All CCVA traits were retained in the full model, showing the same relationships as the previous model. Of the threat factors, 
human intrusion and disturbance became insignificant, while agriculture and aquaculture, natural system modification, and invasive and other problematic species retained their positive effect on climate change threat.

\section{Discussion}

Despite previous criticisms of the IUCN Red List to properly account for climate change as an emerging threat (Thomas et al. 2004; Keith et al. 2014), our analysis suggests that the IUCN Red List assessment process identifies climate change risk for species with certain habitats or traits that may increase climate change risk. Key associations with a climate change-threatened status on the IUCN Red List were the presence of dispersal barriers, occurrence in montane, grassland or intertidal habitats, narrow precipitation tolerance, small population sizes, low genetic diversity, long generation lengths, threats from fire and fire suppression, invasive species, and additional synergistic threats.

Some of these factors are well documented in the published literature and are therefore relatively easy to assess within the current assessment frameworks. For example, distinct geographical barriers, especially those relevant to the CCVA process (mountaintops, islands, etc.; Foden et al. 2013) and species restricted to montane habitats are easily identified by assessors, explaining their tendency to account for climate change threat in these species during an IUCN Red List assessment. This is buoyed by extensive literature on shifting species ranges in response to climate change (Walther et al. 2002), where species which are incapable of shifting their ranges may undergo declines and even extinction (e.g. mountaintop extinctions; Colwell et al. 2008). 
Traits that are often expected (and indeed used) to confer high vulnerability to climate, but were, in our analysis, shown to have negative relationships with the likelihood of a climate change threat classification on the IUCN Red List are of particular interest. These findings challenge the "ecological common sense" approach to designing vulnerability assessment protocols.

Many grassland ecosystems rely on climate-driven processes such as fire (Boughton et al. 2013) and/or flood regimes (Zelnik \& Čarni 2013) to maintain their vegetation composition. Since natural fire/flooding regimes are expected to alter under climate change (Moriondo et al. 2006; Flannigan et al. 2009), species already threatened by or reliant on fire or flooding regimes could become increasingly threatened as climate change increases or disrupts the frequency and severity of these events. Dependence on the presence or absence of a specific fire or flooding regime is already incorporated into some CCVAs (Carr et al. 2014; Böhm et al. 2016), but only threat from altered fire cycles appears to be consistently associated with climate change-threat on the IUCN Red List. The omission of alteration of flooding regimes is somewhat compensated for, given that some dry or flood-reliant habitats were directly associated with climate change-threat on the IUCN Red List. While species in arid regions are adapted to withstand low levels of precipitation, many already operate at critical physiological levels of water (and temperature) requirements and are therefore under particular climate change threat (Vale \& Brito 2015).

Intertidal species will likely face challenges associated with sea level rise, which will reduce the availability of these habitats (Galbraith et al. 2002), particularly where human developments prevent natural migration of coastal habitats inland. Similarly, projected 
increases in the severity and frequency of adverse weather conditions, such as storms, are likely to cause increased damage to seabird breeding sites and increase chick mortality (Croxall et al. 2012; Bonter et al. 2014), while sea level rise is expected to worsen such impacts (Van De Pol et al. 2010). Habitat inundation due to climate change appears to be already considered by many assessors as a threat to species.

Climate change-threatened species were comparatively absent from forest habitats (including montane and tropical forests), most notably the Amazon Basin - a region consistently harbouring the highest numbers of climate change-vulnerable species in global analyses (Foden et al. 2013; Böhm et al. 2016). Forest habitats may effectively buffer against negative impacts of climate change by providing temperature-stabilising microhabitats (e.g. under logs, within soil and leaf litter, epiphytes and tree holes) (Huey \& Tewksbury 2009; Scheffers et al. 2014a; Scheffers et al. 2014b). Given the spatial incongruence of climate changevulnerable species versus climate change-threatened species, CCVAs may overestimate the vulnerability of tropical forest species. This may be specifically through the treatment of microhabitat specialists as climate change-sensitive (Foden et al. 2013), with both habitat and microhabitat specialisation of species potentially having a disproportionate influence on the outcome of vulnerability assessments, while also being difficult to assess objectively across species (Böhm et al. 2016). Red List assessors may instead consider the buffering effects of microhabitats for each species individually. Habitat specificity, measured as the number of habitats recorded in the IUCN Red List assessments, is more easily and objectively assessed, and generally also corresponds to a lower extinction risk (Böhm et al. 2016). 'Generalist' lifehistory and adaptability to environmental change provides species with the opportunity to relocate to refugia from harmful climate change, or to less affected habitats. Empirical research is required to fill trait data gaps and gather evidence of how traits affect climate 
change vulnerability (Böhm et al. 2016) in order to improve CCVAs and allow adequate climate change representation in IUCN Red List assessments.

Climate change is often described as acting synergistically with other, more immediate, threats, such as habitat loss/degradation, invasive species, pollution or overexploitation. We found many threats which significantly co-occurred with a climate change threat on the IUCN Red List. Interactions between pollution and climate change and the subsequent effects on the health of wildlife are becoming increasingly recognized (Noyes \& Lema 2015), including the ability for one stressor to reduce a species' resilience to the other.

Interactions between climate change and invasive species (or inter-specific interactions in the case of CCVA) are well documented, specifically where species cause disease (e.g. amphibians and Chytrid fungus), or where the affected species is an island endemic (Szabo et al. 2012). Disease-related inter-specific interactions may be adequately reflected in Red List assessments of amphibians, especially since the interaction between Chytrid fungus and climate change has received much attention in recent years (Pounds et al. 2006; Lips et al. 2008), despite sometimes tenuous evidence (Rohr et al. 2008; Rohr \& Raffel 2010). It remains unclear from our analyses (although it is unlikely) whether Red List assessors are giving explicit consideration to interactions between threat types; it is more likely that assessors recognise the extreme vulnerability of species to a large number of different threatening processes. 
Assessing broad-scale associations across global data sets comes with certain caveats which may cause spurious results. For example, many bird species known to use marine neritic habitats are noted as climate change-threatened, although the actual impact is likely occurring in other habitats, such as terrestrial breeding sites. Species with large global distributions may vary in their vulnerability to climate change across their range. Therefore, richness maps presented in this paper are only indicative of high numbers of climate change-threatened species, rather than where species will actually be impacted.

Assessments of threat types may vary between assessors due to individual differences in attitudes to risk and perceptions of predominant threat processes affecting a species, and our current analysis does not account for this variability. Accounting for assessors as random effects in a mixed logistic model is unmanageable in reality, given the multitude of assessors and assessor combinations involved in the production of the $15,000+$ assessments in our analysis. While assessor bias may result in inconsistent documentation of threats between IUCN Red List assessments, all assessments in our analysis are reviewed by one of two Red List authorities (BirdLife International and the IUCN SSC Amphibian Specialist Group), ensuring consistency within taxonomic groups undergoing comprehensive assessments (Collen et al. 2016). To overcome assessor bias, next steps should involve the use of machine learning techniques, such as random forests, to predict climate change threat from habitats, threats and CCVA traits. Such techniques have recently been used to predict extinction risk of Data Deficient species on the IUCN Red List (Bland et al. 2015).

We also did not consider any interactions between variables. For example, a species occurring in a particular habitat (e.g. freshwater pools) with an ongoing threat (e.g. 
agricultural water abstraction) may be more susceptible to climate change impacts than a species occupying a similar habitat but unaffected by the compounding threat. This point is particularly topical, given the emerging acknowledgement that human responses to climate change are likely to exacerbate existing threats, and in some cases may be more significant than the direct threats typically associated with climate change (Watson 2014).

Red List assessments can benefit from the findings of trait-based analyses to appropriately consider the impacts of climate change. Specific traits considered in CCVA should be used to assess whether climate change is, or may become, a threat to a species. Using a combination of comparable species' intrinsic and spatial traits to predict the likelihood of climate change threat, Pacifici et al. (2017) further emphasize this requirement, identifying congruence with IUCN Red List assessments for selecting climate change as a threat in only $7 \%$ of mammals and $4 \%$ of birds. The consideration of specific traits used in CCVA has recently been incorporated into official guidance on IUCN Red List assessments (IUCN Standards and Petitions Subcommittee 2016). Such consideration of climate change impact mechanisms (e.g. through use of CCVAs) as part of Red List assessments does not mean more species would be classed as threatened, because assignment of extinction risk categories follows strict criteria, based on symptoms of extinction risk (declining populations, restricted range etc.) (Collen et al. 2016), rather than threat processes per se. However, it would help the documentation of climate change as a potential threat to species for which certain characteristics of high sensitivity and low adaptability overlap with high exposure scenarios in the future. Other factors related to climate change threat may already be included in IUCN Red List assessments through their direct impact on species' extinction risk. For example, while it is unlikely that assessors specifically consider the role of population size in assessing climate change threat, the ready availability of these metrics suggests that simple guidelines 
could be compiled to make assessors aware of these traits and how they may be used, in conjunction with threat maps of climate change exposure (Murray et al. 2014), to assess climate change-threat. Since the effects of climate change are often slow to develop, it is likely that assessors often consider climate change as a threat for species with longer generation lengths.

As described earlier in this discussion, extra consideration should be given to traits that were consistently not associated with climate change threat on the Red List or were found to contradict CCVA hypotheses (e.g. habitat specialism, microhabitat-dependence, temperature tolerance, dependence on environmental triggers, low dispersal capacity, and low reproductive capacity) when assessing climate change threat for the IUCN Red List. However, discrepancies may result from the fact that for some traits, very little direct information exists in the published literature to 1) derive trait values for species or 2) link certain traits solidly to higher climate change impacts. The former may lead to CCVA trait values, e.g. temperature tolerance, being derived from indirect data sources, such as spatial environmental data layers overlaid onto species range maps (Foden et al. 2013). While temperature tolerance measures inferred from spatial data were positively correlated with both critical maximum temperature and critical temperature range in an analysis of temperature tolerance in reptiles (Böhm et al. 2016), indirectly derived trait values may not always adequately reflect a species' biology. Assuming that Foden et al. (2013) adequately inferred species' temperature tolerances, our results suggest that Red List assessors are giving less consideration to temperature requirements compared to other environmental factors, such as precipitation tolerance. It is possible, however, that the method used by Foden et al. (2013) is misleading the apparent positive relationship between temperature tolerance and climate change threat. To infer temperature tolerances, Foden et al. used minimum/maximum 
observed temperatures across species' ranges (using clipped range polygons). This approach fails to account for the fact that some species' (and particularly widespread species) global ranges often comprise locally adapted sub-populations, which can differ in plasticity. Consequently, an apparent ability for a species to tolerate a wide range of conditions across its global range may not hold true when considerations are made using lower (e.g. subpopulation) spatial units. Valladeres et al. (2014) showed that forecasts of species range contractions were even more severe than those using conventional assumptions of consistently high plasticity across a species' range when population differentiation is factored in and dispersal restricted. For most species, however, suitable population-level data are not available. Further research should therefore seek to determine trends of population differentiation in order to fill this gap.

Further research should focus on identifying other logical avenues for research to guide efforts to accumulate much needed empirical evidence on the importance of our highlighted traits in a climate change vulnerability context. This is of particular urgency as many of the less conspicuous or imminent climate change-associated threats may still be very real and severe, even if not within the timeframes used by the planning agency in question and/or the IUCN Red List itself.

\section{Acknowledgements}

MB receives generous support from The Rufford Foundation and the ZSL Mission Opportunities Fund. The authors would also like to thank James Stevens for his help producing the maps.

\section{Supporting Information}


The full list of IUCN CCVA species traits (Appendix S1), IUCN Red List threats (Appendix S2), and IUCN Red List habitats used in this assessment (Appendix S3), as well as sample sizes of all significant IUCN Red List threats (Appendix S4), all significant IUCN Red List habitats (Appendix S5), and all significant CCVA traits (Appendix S6) are available online. The authors are solely responsible for the content and functionality of these materials. Queries (other than absence of the material) should be directed to the corresponding author.

\section{Literature Cited}

Akçakaya HR, Butchart S, Mace GM, Stuart SN, Hilton-Taylor C. 2006. Use and misuse of the IUCN Red List Criteria in projecting climate change impacts on biodiversity. Global Change Biology 12:2037-2043.

Akçakaya HR, Butchart SH, Watson JE, Pearson RG. 2014. Preventing species extinctions resulting from climate change. Nature Climate Change 4:1048-1049.

Bellard C, Bertelsmeier C, Leadley P, Thuiller W, Courchamp F. 2012. Impacts of climate change on the future of biodiversity. Ecology Letters 15:365-377.

Bland LM, Collen B, Orme CDL, Bielby J. 2015. Predicting the conservation status of data-deficient species. Conservation Biology 29:250-259.

Böhm M, Cook D, Ma H, Davidson AD, García A, Tapley B, Pearce-Kelly P, Carr J. 2016. Hot and bothered: using trait-based approaches to assess climate change vulnerability in reptiles. Biological Conservation: 204:32-41.

Bonter DN, MacLean SA, Shah SS, Moglia MC. 2014. Storm-induced shifts in optimal nesting sites: A potential effect of climate change. Journal of Ornithology 155:631-638.

Boughton EH, Bohlen PJ, Steele C. 2013. Season of fire and nutrient enrichment affect plant community dynamics in subtropical semi-natural grasslands released from agriculture. Biological Conservation 158:239-247.

Brook BW, Sodhi NS, Bradshaw CJ. 2008. Synergies among extinction drivers under global change. Trends in Ecology and Evolution 23:453-460. 
Burnham KP, Anderson DR 2002. Model selection and multimodel inference: a practical informationtheoretic approach. Springer, New York, USA.

Carr JA, Hughes AF, Foden WB. 2014. A Climate Change Vulnerability Assessment of West African Species. Cambridge, UK.

Collen B, et al. 2016. Clarifying misconceptions of extinction risk assessment with the IUCN Red List. Biology Letters 12:20150843.

Colwell RK, Brehm G, Cardelús CL, Gilman AC, Longino JT. 2008. Global warming, elevational range shifts, and lowland biotic attrition in the Wet Tropics. Science 322:258-261.

Croxall JP, Butchart SH, Lascelles B, Stattersfield AJ, Sullivan B, Symes A, Taylor PHIL. 2012. Seabird conservation status, threats and priority actions: A global assessment. Bird Conservation International 22:1-34.

ESRI. 2011. ArcGIS Desktop: Release 1. Environmental Systems Research Institute, Redlands, California.

Flannigan M, Stocks B, Turetsky M, Wotton M. 2009. Impacts of climate change on fire activity and fire management in the circumboreal forest. Global Change Biology 15:549-560.

Foden WB, Young BE (eds.) 2016. IUCN SSC Guidelines for Assessing Species' Vulnerability to Climate Change. Version 1.0. Occasional Paper of the IUCN Species Survival Commission No. 59. IUCN Species Survival Commission, Cambridge, UK and Gland, Switzerland. $\mathrm{x}+114 \mathrm{pp}$.

Foden WB, et al. 2013. Identifying the World's Most Climate Change Vulnerable Species: A Systematic Trait-Based Assessment of all Birds, Amphibians and Corals. Plos One 8.

Galbraith H, Jones R, Park R, Clough J, Herrod-Julius S, Harrington B, Page G. 2002. Global Climate Change and Sea Level Rise: Potential Losses of Intertidal Habitat for Shorebirds. Waterbirds: The International Journal of Waterbird Biology 25:173-183.

Hayward MW, Child MF, Kerley GIH, Lindsey PA, Somers MJ, Burns B. 2015. Ambiguity in guideline definitions introduces assessor bias and influences consistency in IUCN Red List status assessments. Frontiers in Ecology and Evolution 3:87. 
Heinze G, Ploner M, Dunkler D, Southworth H. 2013. Package 'logistf': Firth's bias reduced logistic regression.

Hof C, Araújo MB, Jetz W, Rahbek C. 2011. Additive threats from pathogens, climate and land-use change for global amphibian diversity. Nature 480:516-519.

Huey RB, Tewksbury JJ. 2009. Can behaviour douse the fire of climate warming? Proceedings of the National Academy of Sciences 106:3647-3648.

IUCN. 2014. The IUCN Red List of Threatened Species. Version 2014.2, Available from http://www.iucnredlist.org.

IUCN. 2016a. Habitat Classification Scheme (Version 3.1), Available from http://www.iucnredlist.org/technical-documents/classification-schemes/habitatsclassification-scheme-ver3 (accessed 11th May 2016).

IUCN. 2016b. The IUCN Red List of Threatened Species. Version 2016.2, Available from http://www.iucnredlist.org.

IUCN Standards and Petitions Subcommittee. 2016. Guidelines for Using the IUCN Red List Categories and Criteria. Version 12., Available from http://www.iucnredlist.org/documents/RedListGuidelines.pdf.

Keith DA, et al. 2014. Detecting Extinction Risk from Climate Change by IUCN Red List Criteria. Conservation Biology 28:810-819.

Lips KR, Diffendorfer J, Mendelson JR, Sears MW. 2008. Riding the wave: Reconciling the roles of disease and climate change in amphibian declines. PLoS Biology 6:441-454.

Moriondo M, Good P, Durao R, Bindi M, Giannakopoulos C, Corte-Real J. 2006. Potential impact of climate change on fire risk in the Mediterranean area. Climate Research 31:85-95.

Murray KA, Verde Arregoitia LD, Davidson A, Di Marco M, Di Fonzo MMI. 2014. Threat to the point: improving the value of comparative extinction risk analysis for conservation action. Global Change Biology 20:483-494.

Noyes PD, Lema SC. 2015. Forecasting the impacts of chemical pollution and climate change interactions on the health of wildlife. Current Zoology 61:669-689. 
Pacifici M, et al. 2015. Assessing species vulnerability to climate change. Nature Climate Change 5:215-225.

Pacifici M., Visconti P, Butchart SH, Watson JE, Cassola FM, Rondinini C. 2017. Species' traits influenced their response to recent climate change. Nature Climate Change: in press.

Pearson RG, et al. 2014. Life history and spatial traits predict extinction risk due to climate change. Nature Climate Change 4:217-221.

Pounds JA, et al. 2006. Widespread amphibian extinctions from epidemic disease driven by global warming. Nature 439:161-167.

R Core Team. 2015. R: A Language and Environment for Statistical Computing. R Foundation for Statistical Computing, Vienna, Austria.

Rohr JR, Raffel TR. 2010. Linking global climate and temperature variability to widespread amphibian declines putatively caused by disease. Proceedings of the National Academy of Sciences of the United States of America 107:8269-8274.

Rohr JR, Raffel TR, Romansic JM, McCallum H, Hudson PJ. 2008. Evaluating the links between climate, disease spread, and amphibian declines. Proceedings of the National Academy of Sciences of the United States of America 105:17436-17441.

Salafsky N, et al. 2008. A standard lexicon for biodiversity conservation: unified classifications of threats and actions. Conservation Biology 22:897-911.

Scheffers BR, Edwards DP, Diesmos A, Williams SE, Evans TA. 2014a. Microhabitats reduce animal's exposure to climate extremes. Global Change Biology 20:495-503.

Scheffers BR, Evans TA, Williams SE, Edwards DP. 2014b. Microhabitats in the tropics buffer temperature in a globally coherent manner. Biology Letters 10:20140819.

Szabo JK, Khwaja N, Garnett ST, Butchart SHM. 2012. Global patterns and drivers of avian extinctions at the species and subspecies level. PLoS One 7:e47080.

Thomas CD, et al. 2004. Extinction risk from climate change. Nature 427:145-148.

Vale CG, Brito JC. 2015. Desert-adapted species are vulnerable to climate change: Insights from the warmest region on Earth. Global Ecology and Conservation 4:369-379. 
Valladares F, et al. 2014. The effects of phenotypic plasticity and local adaptation on forecasts of species range shifts under climate change. Ecology Letters 17:1351-1364.

Van De Pol M, et al. 2010. Do changes in the frequency, magnitude and timing of extreme climatic events threaten the population viability of coastal birds? Journal of Applied Ecology 47:720730.

Walther GR, Post E, Convey P, Menzel A, Parmesan C, Beebee TJC, Fromentin JM, Hoegh-Guldberg O, Bairlein F. 2002. Ecological responses to recent climate change. Nature 416:389-395.

Watson JE. 2014. Human responses to climate change will seriously impact biodiversity conservation: it's time we start planning for them. Conservation Letters 7:1-2.

Zelnik I, Čarni A. 2013. Plant species diversity and composition of wet grasslands in relation to environmental factors. Biodiversity and Conservation 22:2179-2192. 


\section{Tables}

Table 1. Logistic regression MAM outputs for amphibians and birds showing all significant Level 1 (bold) and corresponding Level 2 habitat classification categories (if any).

\begin{tabular}{|c|c|c|c|c|c|}
\hline \multicolumn{2}{|c|}{ IUCN habitat category ${ }^{a}$} & $\beta$ coeff & $\begin{array}{l}\text { t. err. } \\
\text { ( } \beta)\end{array}$ & Wald's $\chi^{2 b}$ & $\begin{array}{l}\text { Odds } \\
\text { ratio }^{c}\end{array}$ \\
\hline \multirow{14}{*}{ 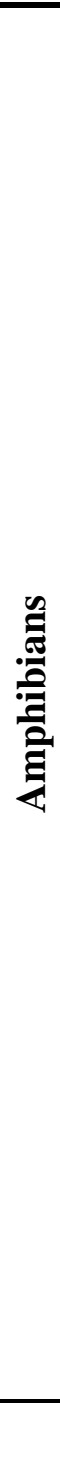 } & Artificial-Terrestrial & -0.421 & 0.129 & $10.621 * *$ & 0.656 \\
\hline & Arable Land & 0.515 & 0.188 & $7.469 * *$ & 1.674 \\
\hline & ST/T Heavily Degraded Former Forest & -0.922 & 0.205 & $20.196 * * *$ & 0.398 \\
\hline & Grassland & 0.447 & 0.142 & $9.878 * *$ & 1.564 \\
\hline & ST/T High Altitude Grassland & 0.709 & 0.159 & $20.017 * * *$ & 2.032 \\
\hline & $\begin{array}{l}\text { ST/T Seasonally Wet/Flooded Lowland } \\
\text { Grassland }\end{array}$ & -1.332 & 0.519 & $6.600 *$ & 0.264 \\
\hline & Savanna & -1.271 & 0.284 & $20.026 * * *$ & 0.281 \\
\hline & Moist Savanna & -1.288 & 0.428 & $9.072 * *$ & 0.276 \\
\hline & Shrubland & 0.317 & 0.144 & $4.822 *$ & $\mathbf{1 . 3 7 3}$ \\
\hline & ST/T Dry Shrubland & 0.523 & 0.217 & $5.818 *$ & 1.687 \\
\hline & ST/T Moist Shrubland & -0.881 & 0.425 & $4.297 *$ & 0.414 \\
\hline & Constant & -2.303 & 0.153 & $226.653 * * *$ & 0.1 \\
\hline & Constant & -2.461 & 0.062 & $1575.852 * * *$ & 0.085 \\
\hline & Artificial-Terrestrial & -0.613 & 0.071 & $74.563 * * *$ & 0.542 \\
\hline \multirow{3}{*}{$\sum_{0}^{\infty}$} & Arable Land & -0.45 & 0.101 & $19.865 * * *$ & 0.638 \\
\hline & ST/T Heavily Degraded Former Forest & -1.124 & 0.138 & $66.635 * * *$ & 0.325 \\
\hline & Forest & -0.256 & 0.08 & $10.330 * * *$ & 0.774 \\
\hline
\end{tabular}




\begin{tabular}{|c|c|c|c|c|}
\hline ST/T Dry Forest & -0.234 & 0.099 & $5.603 *$ & 0.791 \\
\hline ST/T Moist Lowland Forest & -0.741 & 0.071 & $108.347 * * *$ & 0.476 \\
\hline ST/T Moist Montane Forest & -0.283 & 0.07 & $16.201 * * *$ & 0.753 \\
\hline ST/T Swamp Forest & -1.149 & 0.241 & $22.829 * * *$ & 0.317 \\
\hline Grassland & 0.4 & 0.078 & $26.677 * * *$ & 1.493 \\
\hline Marine Intertidal & 0.315 & 0.113 & $7.823 * *$ & 1.37 \\
\hline Marine Neritic & 0.987 & 0.105 & $89.095 * * *$ & 2.682 \\
\hline Savanna & -0.609 & 0.107 & $32.456 * * *$ & 0.544 \\
\hline Dry Savanna & -0.787 & 0.111 & $50.396 * * *$ & 0.455 \\
\hline Constant & -1.945 & 0.08 & $592.825 * * *$ & 0.143 \\
\hline Constant & -1.445 & 0.047 & $960.690 * * *$ & 0.236 \\
\hline
\end{tabular}

\footnotetext{
${ }^{a}$ Level 1 and level 2 habitat classification categories were analysed separately. For every category the $d f=1 . \quad \mathrm{ST} / \mathrm{T}=$ Subtropical/Tropical. bLevels of significance are denoted with '*' for $P<0.05$, '**' for $P<0.01$, and '***' for $P$ $<0.001$.

${ }^{\mathrm{c}}$ Odds ratios indicate the likelihood of a climate change threat classification on the Red List for each category.
} 
Table 2. Logistic regression MAM outputs for amphibians and birds showing all significant Level 1 (bold) and corresponding Level 2 threat classification categories (if any).

\begin{tabular}{|c|c|c|c|c|c|}
\hline \multirow{2}{*}{\multicolumn{2}{|c|}{ IUCN threat category ${ }^{\mathrm{a}}$}} & \multirow{2}{*}{\multicolumn{2}{|c|}{$\begin{array}{lc}\text { St. err. } \\
\\
(\beta)\end{array}$}} & \multirow[b]{2}{*}{ Wald's $\chi^{2 b}$} & \multirow{2}{*}{$\begin{array}{l}\text { Odds } \\
\text { ratio }^{c}\end{array}$} \\
\hline & & & & & \\
\hline \multirow{10}{*}{ 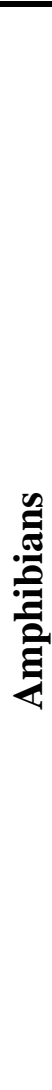 } & Human Intrusions and Disturbance & 0.689 & 0.175 & $11.546 * * *$ & 1.992 \\
\hline & Recreational Activities & 0.821 & 0.183 & $20.205 * * *$ & 2.273 \\
\hline & $\begin{array}{l}\text { Invasive and Other Problematic Species, Genes } \\
\text { and Diseases }\end{array}$ & 1.494 & 0.114 & $172.45 * * *$ & 4.455 \\
\hline & Invasive Non-Native/Alien Species/Diseases & 1.555 & 0.111 & $196.22 * * *$ & 4.735 \\
\hline & Natural System Modifications & 0.905 & 0.113 & $63.936 * * *$ & 2.472 \\
\hline & Fire and Fire Suppression & 1.107 & 0.12 & $84.953 * * *$ & 3.025 \\
\hline & Pollution & 0.687 & 0.114 & $36.518 * * *$ & 1.988 \\
\hline & Agricultural and Forestry Effluents & 0.814 & 0.113 & $51.754 * * *$ & 2.257 \\
\hline & Constant & -3.776 & 0.121 & $971.82 * * *$ & 0.023 \\
\hline & Constant & -3.612 & 0.095 & $1449.9 * * *$ & 0.027 \\
\hline \multirow{7}{*}{$\sum_{0}^{\infty}$} & Agriculture and Aquaculture & 1.123 & 0.096 & $137.55 * * *$ & 3.074 \\
\hline & Annual and Perennial Non-Timber Crops & 1.157 & 0.089 & $170.04 * * *$ & 3.18 \\
\hline & Human Intrusions and Disturbance & 0.335 & 0.128 & $6.849 * *$ & 1.398 \\
\hline & Recreational Activities & 0.589 & 0.166 & $12.603 * * *$ & 1.802 \\
\hline & Work and Other Activities & 0.436 & 0.177 & $6.071^{*}$ & 1.547 \\
\hline & $\begin{array}{l}\text { Invasive and Other Problematic Species, Genes } \\
\text { and Diseases }\end{array}$ & 2.214 & 0.092 & $581 * * *$ & 9.152 \\
\hline & Invasive Non-Native/Alien Species/Diseases & 2.277 & 0.899 & $641.3 * * *$ & 9.747 \\
\hline
\end{tabular}


Problematic Native Species/Diseases

Natural System Modifications

Fire and Fire Suppression

\section{Constant}

Constant

\section{$\begin{array}{llll}0.329 & 0.104 & 10.005 * * & 1.39\end{array}$}

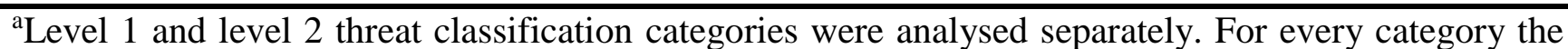
$\begin{array}{lllll}d f & = & \mathrm{ST} / \mathrm{T} & = & \text { Subtropical/Tropical. }\end{array}$ ${ }^{b}$ Levels of significance are denoted with '*' for $P<0.05$, '**' for $P<0.01$, and '***' for $P<0.001$. ${ }^{c}$ Odds ratios indicate the likelihood of a climate change threat classification on the Red List for each category.
} 
Table 3. Logistic regression MAM output for amphibians and birds showing all significant species' sensitivity and adaptability traits used by the CCVA.

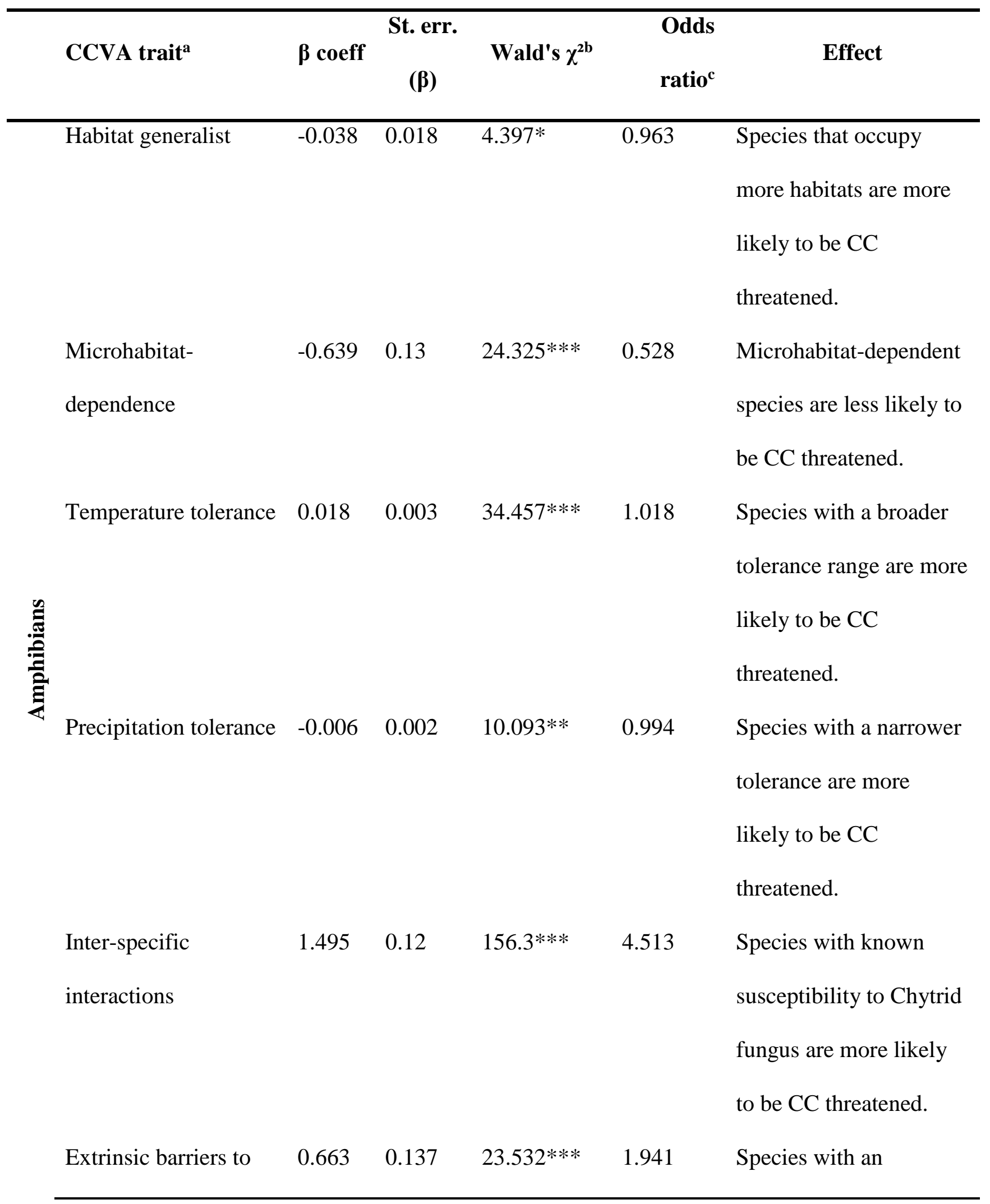


dispersal

extrinsic dispersal

barrier are more likely

to be $\mathrm{CC}$ threatened.

\begin{tabular}{lllll}
\hline Constant & -2.754 & 0.204 & $182.277 * * *$ & 0.064
\end{tabular}

Microhabitat-

$\begin{array}{ll}-0.945 & 0.297\end{array}$

$12.686^{* * *}$

0.389

Microhabitat-dependent

dependence

species are less likely to

be $\mathrm{CC}$ threatened.

Temperature tolerance $\quad 0.012 \quad 0.002 \quad 39.431 * * * \quad 1.012 \quad$ Species with a broader

tolerance range are more

likely to be $\mathrm{CC}$

threatened.

Precipitation tolerance $-0.008 \quad 0.002 \quad 20.055^{* * *} \quad 0.992 \quad$ Species with a narrower

tolerance range are more

likely to be $\mathrm{CC}$

:

Small population size $\quad 1.566 \quad 0.144 \quad$ Inf.***

4.787 Species with a small

population size are more

likely to be $\mathrm{CC}$

threatened.

Extrinsic barriers to $\quad 8.269 \quad 0.438 \quad$ Inf.*** $3901.05 \quad$ Species with barriers to dispersal dispersal are more likely to be $\mathrm{CC}$ threatened.

Low genetic diversity $1.109 \quad 0.37 \quad 8.198 * * \quad 3.031 \quad$ Species with low genetic diversity are more likely to be $\mathrm{CC}$ 
threatened.

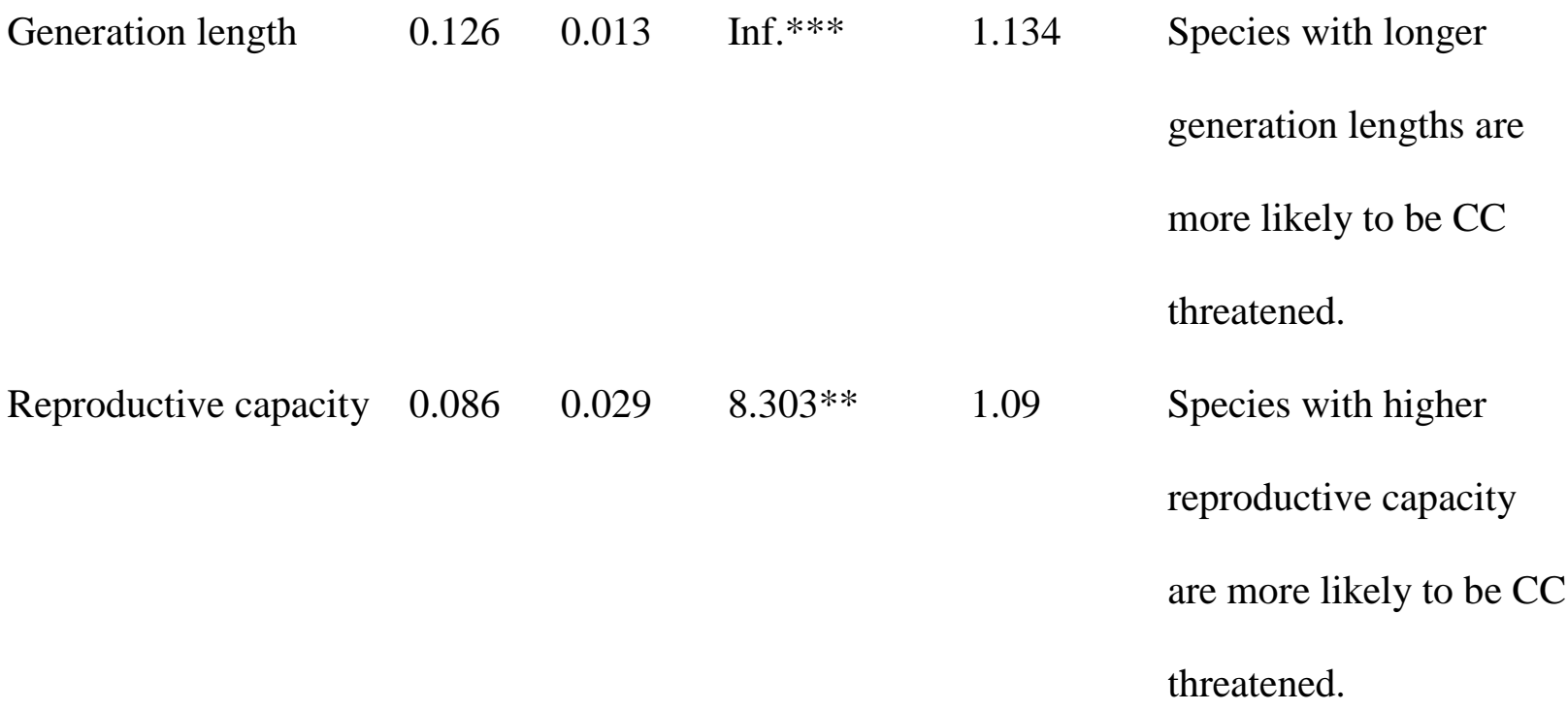

\begin{tabular}{lllll}
\hline Constant & -4.463 & 0.171 & Inf.*** & 0.012
\end{tabular}

${ }^{\mathrm{a}}$ For every category the $\mathrm{df}=1$.

${ }^{b}$ Levels of significance are denoted with '*' for $\mathrm{P}<0.05$, '**' for $\mathrm{P}<0.01$, and '***' for $\mathrm{P}<0.001$. ${ }^{\mathrm{c}}$ Odds ratios indicate the likelihood of a climate change threat classification on the Red List for each category. 
Table 4. Logistic regression MAM output for amphibians and birds showing all significant Level 1 habitat and threat classification categories, and species' CCVA sensitivity and adaptability traits (divided by dashed lines).

\begin{tabular}{|c|c|c|c|c|c|}
\hline & & & St. er & & Odds \\
\hline & Independent variables ${ }^{a}$ & $\beta$ coeff & (及) & Wald's $\chi^{2 b}$ & ratioc \\
\hline & Grassland & 0.436 & 0.135 & $10.375^{* *}$ & 1.547 \\
\hline & Human Intrusions and Disturbance & 0.553 & 0.181 & $9.364 * *$ & 1.738 \\
\hline & Natural System Modifications & 0.831 & 0.117 & $50.098 * * *$ & 2.296 \\
\hline & Invasive and Other Problematic Species, & 1.167 & 0.133 & $76.913 * * *$ & 3.212 \\
\hline & Genes and Diseases & & & & \\
\hline : & Pollution & 0.672 & 0.123 & $29.888 * * *$ & 1.958 \\
\hline 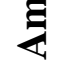 & Microhabitat-dependence & -0.803 & 0.127 & $40.12 * * *$ & 0.448 \\
\hline & Temperature tolerance & 0.009 & 0.003 & $7.601 * *$ & 1.009 \\
\hline & Precipitation tolerance & -0.004 & 0.002 & $4.796^{*}$ & 0.996 \\
\hline & Inter-specific interactions & 0.752 & 0.135 & $31.259 * * *$ & 2.121 \\
\hline & Extrinsic barriers to dispersal & 0.483 & 0.143 & $11.438 * * *$ & 1.621 \\
\hline & Constant & -3.326 & 0.218 & $233.784 * * *$ & 0.036 \\
\hline & Marine Neritic & 1.32 & 0.219 & $33.373 * * *$ & 3.743 \\
\hline & Agriculture and Aquaculture & 0.983 & 0.171 & $32.131 * * *$ & 2.672 \\
\hline & Natural System Modifications & 0.699 & 0.175 & $15.289 * * *$ & 2.012 \\
\hline$\overbrace{0}^{n}$ & Invasive and Other Problematic Species, & 1.351 & 0.162 & $66.597 * * *$ & 3.861 \\
\hline & Genes and Diseases & & & & \\
\hline & Microhabitat-dependence & -0.699 & 0.3 & $6.319^{*}$ & 0.497 \\
\hline & Temperature tolerance & 0.01 & 0.002 & $22.677 * * *$ & 1.01 \\
\hline
\end{tabular}




\begin{tabular}{lllcc} 
Precipitation tolerance & -0.008 & 0.002 & $16.861^{* * *}$ & 0.992 \\
Small population size & 0.453 & 0.17 & $6.942^{* *}$ & 1.573 \\
Extrinsic barriers to dispersal & 8.345 & 0.439 & Inf.*** & 4209.08 \\
Low genetic diversity & 0.912 & 0.388 & $5.283^{* *}$ & 2.489 \\
Generation length & 0.047 & 0.016 & $8.106^{* *}$ & 1.048 \\
Reproductive capacity & 0.076 & 0.029 & $6.309^{*}$ & 1.079 \\
\hline Constant & -4.454 & 0.185 & Inf.**** & 0.012
\end{tabular}

${ }^{\mathrm{a}}$ For every category the $\mathrm{df}=1$.

${ }^{\mathrm{b}}$ Levels of significance are denoted with '*' for $\mathrm{P}<0.05$, '**' for $\mathrm{P}<0.01$, and '***' for $\mathrm{P}$ $<0.001$.

${ }^{\mathrm{c}}$ Odds ratios indicate the likelihood of a climate change threat classification on the Red List for each category. 


\section{Figure legends}

Figure 1. Equal-area projections of global species richness of amphibians (A); total numbers of amphibian species assessed as climate change-vulnerable during CCVA (Foden et al. 2013) (B); total numbers of amphibian species with climate change threat listed on the IUCN Red List (IUCN 2014) (C); percentage (of the total species present) of amphibians assessed as climate change-vulnerable during CCVA (Foden et al. 2013) (D); and percentage (of total species present) of amphibians possessing climate change as a listed threat on the IUCN Red List (IUCN 2014) (E).

Figure 2. Equal area-projections of global species richness of birds (A); total numbers of bird species assessed as climate change-vulnerable during CCVA (Foden et al. 2013) (B); total numbers of bird species with climate change threat listed on the IUCN Red List (IUCN 2014) (C); percentage (of the total species present) of birds assessed as climate change-vulnerable during CCVA (Foden et al. 2013) (D); and percentage (of total species present) of birds possessing climate change as a listed threat on the IUCN Red List (IUCN 2014) (E). 
Figure 1.

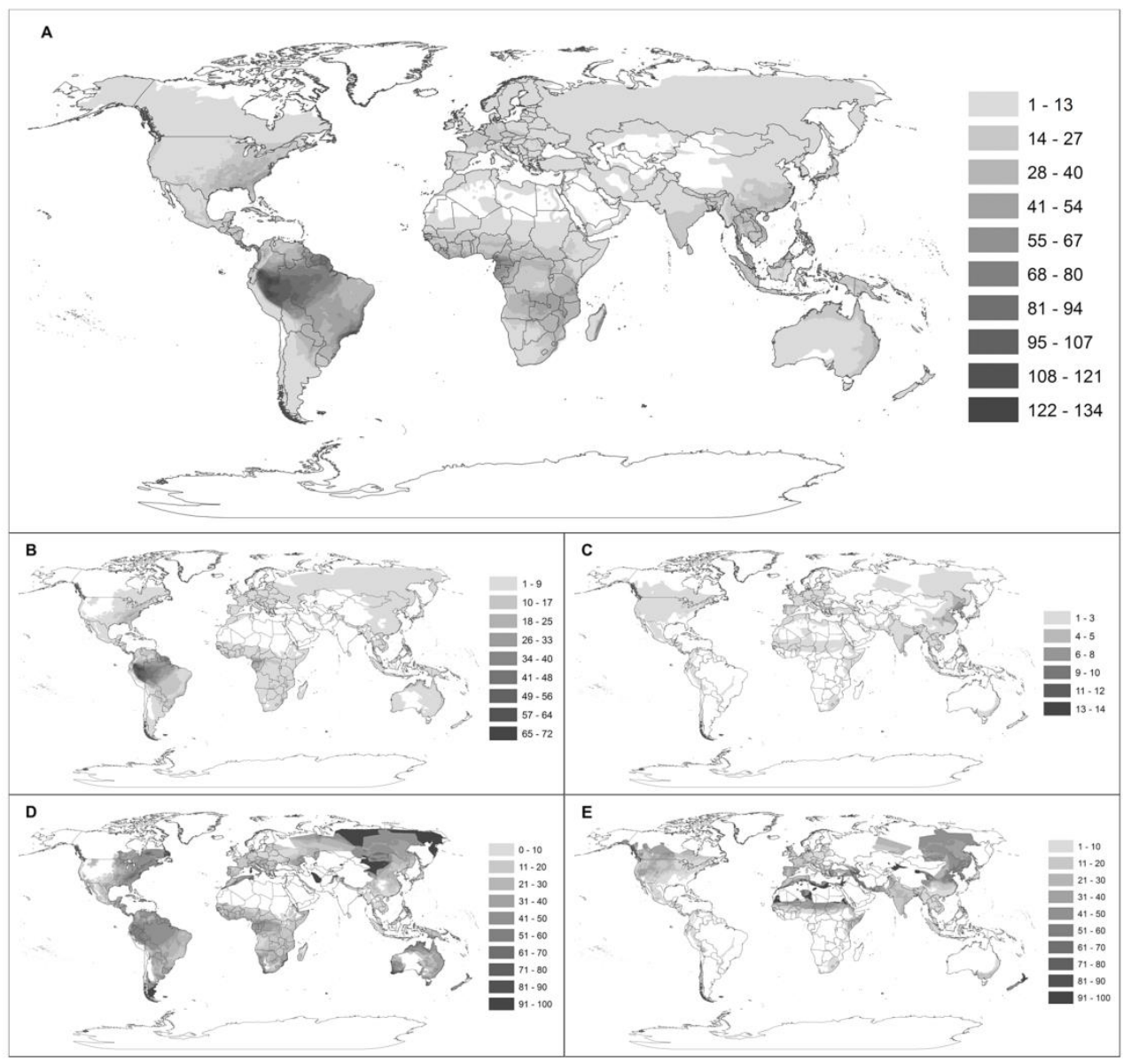


Figure 2.

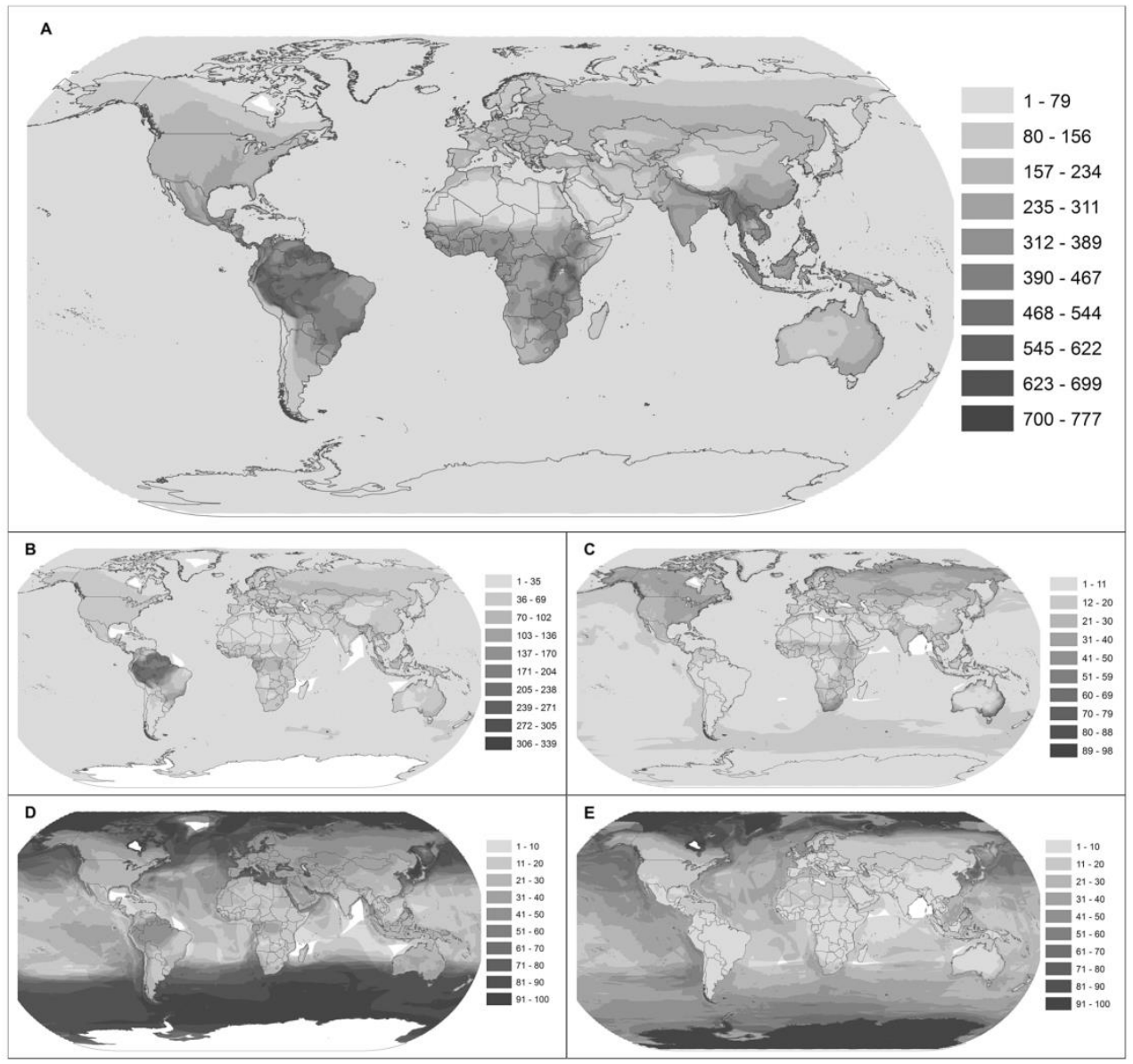

